\title{
The Biphasic Effect of Amrinone on Tension Development in Newborn Mammalian Myocardium
}

\author{
THOMAS S. KLITZNER, YEHUDA SHAPIR, ${ }^{1}$ ROSS RAVIN, AND WILLIAM F. FRIEDMAN
}

The Division of Pediatric Cardiology, Department of Pediatrics, UCLA School of Medicine and UCLA Medical Center, Los Angeles, California 90024

\begin{abstract}
The effect of the bipyridine compound, amrinone, on tension generation in neonatal and adult myocardium was studied over the concentration range 30-500 $\mu \mathrm{g} / \mathrm{mL}$. Increasing concentrations of amrinone caused a monotonic increase in twitch tension and the rate of tension development in adult papillary muscles. In contrast, lower concentrations of amrinone (30 and $100 \mu \mathrm{g} / \mathrm{mL}$ ) caused a decrease in twitch tension and $\mathrm{dP} / \mathrm{dt}$ in newborn papillary muscles, whereas $500 \mu \mathrm{g} / \mathrm{mL}$ amrinone caused a significant increase in both parameters in the younger age group. Lactic acid, used to dissolve amrinone, was shown to have no effect on tension development. Half relaxation time was decreased in adult preparations at all concentrations of amrinone. In comparison, the decrease in half relaxation time produced by amrinone in the newborn was significant only at a concentration of $500 \mu \mathrm{g} / \mathrm{mL}$. Action potential duration in the newborn was significantly shortened by 30 $\mu \mathrm{g} / \mathrm{mL}$ amrinone. In voltage clamp experiments, $30 \mu \mathrm{g} / \mathrm{mL}$ amrinone was shown to have no effect on tension accompanying two second voltage clamp steps to the plateau potential in newborn myocardium. Developed tension at $400 \mathrm{~ms}$ into the clamp step, final tension, and the ratio of early peak tension to final tension were all unchanged by the low concentration of amrinone. In contrast, $500 \mu \mathrm{g} / \mathrm{mL}$ amrinone in the newborn increased tension at $\mathbf{4 0 0} \mathrm{ms}$ and final tension but had no effect on the ratio of early peak tension to final tension. These results suggest that the negative inotropic effect of lower concentrations of amrinone on neonatal myocardium is the result of changes in action potential configuration and not a true alteration in basic mechanisms of intracellular $\mathrm{Ca}^{2+}$ regulation. Further, the positive inotropic effect of higher concentrations of amrinone appears to result from enhancement of transmembrane $\mathrm{Ca}^{2+}$ influx as well as augmentation of $\mathrm{Ca}^{2+}$ sequestration and rerelease by the sarcoplasmic reticulum. (Pediatr Res 27: 144-147, 1990)
\end{abstract}

Abbreviations

SR, sarcoplasmic reticulum

$\mathrm{dP} / \mathrm{dt}$, the first derivative of tension development

HRT, half relaxation time

$T_{400}$, tension measured at $400 \mathrm{~ms}$ into a voltage clamp step

Received May 19, 1989; accepted September 29, 1989

${ }^{1}$ Present address Pediatric Cardiology, SUNY Health Science Center at Brooklyn, Brooklyn, NY 11203.

Correspondence and reprints: Thomas S. Klitzner, M.D., Ph.D., Department of Pediatrics, B2-427 MDCC, UCLA School of Medicine, Los Angeles, CA 90024

Supported in part by funding from the NIH (K08 HL01347 and R01 HL35783) and the American Heart Association, Greater Los Angeles Affiliate (829 GI and $788 \mathrm{IG})$
$T_{\text {tonic, }}$ tension measured at the end of a voltage clamp step $P / T$, the ratio of phasic to tonic tension

Amrinone, a synthetic bipyridine derivative, has been used to treat chronic congestive heart failure in adults $(1-3)$. Previous research on mature guinea pig papillary muscles indicates that amrinone causes a concentration-dependent increase in cAMP levels by inhibiting phosphodiesterase $(4,5)$. In addition, amrinone's positive inotropic effect may be linked to an increase in $\mathrm{Ca}^{2+}$ influx via the slow inward current $(6,7)$. In contrast, previous studies on immature myocardium suggest that amrinone has no inotropic effect in the neonatal period (8), or may, in fact, depress myocardial force development in this age group (9-11). It has been suggested that age-related changes in the inotropic response of cardiac tissue to amrinone may be due, in part, to the age dependent development of t-tubules and SR (11, 12).

In our study, the dose response curve for amrinone has been extended into a previously unexplored concentration range revealing a biphasic response of neonatal myocardium to increasing concentrations of amrinone. The mechanism underlying both the negative inotropic effect of low dose amrinone and the biphasic response to an extended range of amrinone concentrations in the newborn have been explored using the single sucrose gap voltage clamp technique. This approach has been used previously in developing myocardium to determine the contribution to tension generation of membrane electrical activity and transsarcolemmal $\mathrm{Ca}^{2+}$ influx as compared to other steps in excitation contraction coupling such as $\mathrm{Ca}^{2+}$ release from the SR $(13,14)$.

\section{MATERIALS AND METHODS}

Preparation and experimental apparatus. Studies were carried out using right ventricular papillary muscles $(0.3-0.9 \mathrm{~mm}$ in diameter) from newborn ( $<10 \mathrm{~d}$ of age) and adult New Zealand White rabbits. Animals were heparinized $(150 \mathrm{U} / \mathrm{kg})$, and anesthetized with intravenous or intraperitoneal sodium pentobarbital $(50 \mathrm{mg} / \mathrm{kg})$. The heart was rapidly excised and muscles were isolated and placed in a three-compartment single sucrose gap chamber. Only one papillary muscle was dissected from each animal. Preparations were stimulated at 12 shocks/min by passing current across the sucrose gap to depolarize the physiologic portion of the muscle. Membrane potential was measured using conventional $3 \mathrm{M} \mathrm{KCl}$ filled glass microelectrodes. Tension was measured using a Grass (Quincy, MA) force-displacement transducer (model FT03C), and dP/dt was measured using a Gould (Cleveland, $\mathrm{OH}$ ) differentiator (model 13-4214-01). All physio- 
logic parameters were recorded on a Gould chart recorder (Brush model 440 ) at $25 \mathrm{~mm} / \mathrm{s}$ or photographed from a Tektronix (Beaverton, OR) storage oscilloscope (model 5113) for later measurement and analysis. Because the size of preparations in the physiologic portion of the experimental chamber was variable, twitch tension and $\mathrm{dP} / \mathrm{dt}$ are reported as a percentage of control values.

HRT was measured from the peak of the twitch to the point at which tension returned to $50 \%$ of peak twitch height. HRT was used as a measure of $\tau$, the time constant of relaxation (15) as follows. Relaxation was assumed to follow an exponential time course. Accordingly,

$$
T_{r}=A e^{-t / \tau}
$$

where $T_{r}=$ tension during relaxation; $A=a$ constant; $t=$ time, and $\tau=$ the relaxation time constant.

It follows that if $t$ is set to 0 at the peak of the twitch,

$$
\mathrm{Ae}^{-(0 / \tau)} / \mathrm{Ae}^{-(\mathrm{HRT} / \tau)}=2
$$

By rearranging the equation and taking the log of both sides,

$$
\tau=\mathrm{HRT} / \ln 2
$$

or HRT is proportional to $\tau$.

Action potential duration was measured from the upstroke of the action potential to the point at which a line drawn tangent to rapid repolarization (phase 3 ) crossed the resting potential. In some experiments this measurement was performed on action potentials measured by electrodes spanning the sucrose gap (16).

Individual muscles were used in either dose response or voltage clamp experiments but not both. Amrinone dose response experiments were performed on two groups of muscles, an adult group $(n=6)$ and a neonatal group $(n=7)$. Voltage clamp experiments were performed on two groups of neonatal muscles, a low dose amrinone group $(n=5)$ and a high dose amrinone group $(n=6)$. To insure that the three groups of neonatal papillary muscles were not different, the mean control twitch tension was compared between groups using a two-tailed $t$ test and found not to be significantly different (newborn dose response group, $72 \pm 9 \mathrm{mg}$; low dose amrinone group, $64 \pm 15$ $\mathrm{mg}$; high dose amrinone group; $91 \pm 13 \mathrm{mg}$, mean $\pm \mathrm{SEM}, p>$ 0.1 ).

Solutions. Four basic solutions were used. The composition is given below in mM. Tyrode's solution: $\mathrm{NaCl}, 120 ; \mathrm{CaCl}_{2}, 1.5$; glucose, 5.6; $\mathrm{MgCl}_{2}, 1.0 ; \mathrm{KCl}, 4.0 ; \mathrm{NaHCO}_{3}, 25 ;$ and $\mathrm{NaH}_{2} \mathrm{PO}_{4}$, 0.44 . Isosmotic sucrose: sucrose, 280 (sucrose dissolved in deionized water contaminated with $10^{-5} \mathrm{M} \mathrm{MnSO}_{4}$ ). KCl-Tyrode's: $\mathrm{KCl}, 128 ; \mathrm{KHCO}_{3}, 24$.

Fresh amrinone stock solution was prepared daily by dissolving $100 \mathrm{mg}$ of amrinone in $0.6 \mathrm{~mL}$ of $0.5 \mathrm{~N}$ lactic acid and diluting to $10 \mathrm{mg} / \mathrm{mL}$. Stock solution was added to Tyrode's solution to achieve final amrinone concentrations of $30,100,200$, and 500 $\mu \mathrm{g} / \mathrm{mL}$. All solutions were bubbled with $95 \% \mathrm{O}_{2}, 5 \% \mathrm{CO}_{2}$ and, if necessary, up to $5 \mathrm{mM}$ additional $\mathrm{NaHCO}_{3}$ was added to maintain the $\mathrm{pH}$ in the range 7.37-7.43.

Control solutions were prepared containing concentrations of lactic acid identical to the lactic acid concentrations in the solutions containing amrinone, The concentrations are $0.24,0.8$, 1.6 , and $4.0 \mathrm{mM}$ (corresponding to solutions containing 30,100 , $200,500 \mu \mathrm{g} / \mathrm{mL}$ of amrinone, respectively).

Experimental procedure. To determine dose response curves, amrinone was added to Tyrode's solution bathing the physiologic portion of the preparation after a 90-min equilibration period. The concentration of amrinone was increased sequentially (30, $100,200,500 \mu \mathrm{g} / \mathrm{mL}$ ) every $15 \mathrm{~min}$. Measurements of physiologic parameters (tension, $\mathrm{dP} / \mathrm{dt}, \mathrm{HRT}$ ) were made before addition of amrinone and at the end of each 15 -min test period.

In voltage clamp experiments, after the initial equilibration period, $2 \mathrm{~s}$ voltage clamp steps to $+10 \mathrm{mV}$ were imposed. Muscles were then exposed to amrinone at a concentration of either 30 or $500 \mu \mathrm{g} / \mathrm{mL}$ for $15 \mathrm{~min}$ and the clamp steps repeated. Before and after addition of amrinone measurements were made of $\mathrm{T}_{400}$ and $\mathrm{T}_{\text {tonic }}$. In addition, the $\mathrm{P} / \mathrm{T}$ ratio was calculated. The details of the single sucrose gap chamber and voltage clamp technique including validity, limitations, and application to neonatal rabbit papillary muscles have been discussed previously $(13,14,16)$.

Statistical methods. Dose response curves were constructed using data expressed as percent of control and evaluated using an analysis of repeated measures (17). Measurements of experimental variables were considered significantly different from control if the control value $(100 \%)$ was outside the $95 \%$ confidence limits around the mean for the measurement. Action potential duration and tension measurements from voltage clamp experiments, pre- and postamrinone, were compared using paired, two-tailed $t$ tests. Differences were considered significant at $p<0.05$.

\section{RESULTS}

Effects of amrinone on twitch tension and $d P / d t$. Figure 1 shows original records from a typical dose response experiment. In adult heart, twitch tension increased with each increase in amrinone concentration. In contrast, twitch tension decreased in the newborn at amrinone concentrations of 30 and $100 \mu \mathrm{g} / \mathrm{mL}$. However, twitch tension increased significantly in the newborn at an amrinone concentration of $500 \mu \mathrm{g} / \mathrm{mL}$. The results for all dose response experiments are summarized in graphical form in Figure 2.

Effects of lactic acid on tension. Because amrinone must be dissolved in lactic acid, experiments were carried out to determine the effect of lactic acid alone on tension development. As shown in Figure 3, lactic acid had no significant effect on twitch tension in either age group.

Effect of amrinone on relaxation. To test the effect of amrinone on relaxation, HRT was measured in each age group at each concentration of amrinone. HRT is plotted as a function of amrinone concentration in Figure 4. Amrinone caused a significant decrease in HRT in the adult at all concentrations tested. In contrast, in the newborn, relaxation was unchanged by amrinone at concentrations below $200 \mu \mathrm{g} / \mathrm{mL}$. The decrease in HRT produced by amrinone in the newborn was significant only at a concentration of $500 \mu \mathrm{g} / \mathrm{mL}$.

Effect of low dose amrinone on action potential duration. To determine whether changes in membrane electrical activity might partially account for the negative inotropic effect of low dose amrinone in the newborn, action potential duration was measured just before and immediately after a 15-min exposure to 30 $\mu \mathrm{g} / \mathrm{mL}$ amrinone. Action potentials were recorded for 11 newborn muscles, six from the dose response group and five from

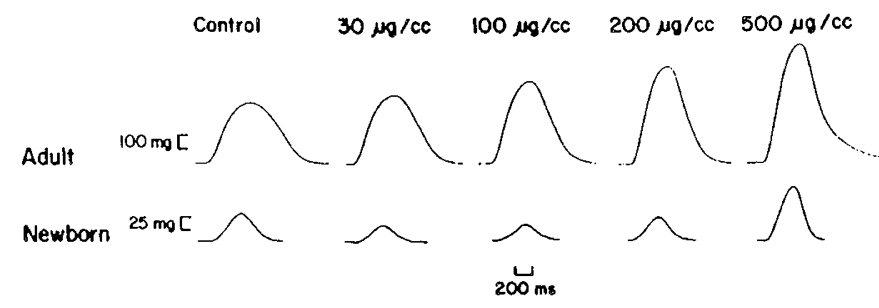

Fig. 1. Tracings from typical adult and newborn papillary muscles exposed to increasing concentrations of amrinone are shown. Muscles were perfused with Tyrode's solution containing $1.5 \mathrm{mM} \mathrm{CaCl}_{2}$ for 90 min before addition of amrinone. Amrinone was added in concentrations of $30,100,200,500 \mu \mathrm{g} / \mathrm{mL}$ at 15 -min intervals. The tracings displayed were recorded at the end of each 15-min interval. Note that in the adult, amrinone caused a monotonic increase in developed tension and $\mathrm{dP} / \mathrm{dt}$ with increasing amrinone concentration. In contrast, in the newborn, amrinone depressed both tension and $\mathrm{dP} / \mathrm{dt}$ at 30 and $100 \mu \mathrm{g} / \mathrm{mL}$. At $200 \mu \mathrm{g} / \mathrm{mL}$ tension returned to control level, and at $500 \mu \mathrm{g} / \mathrm{mL}$ there is a marked positive inotropic effect . (temperature $=23^{\circ} \mathrm{C}$ ) 

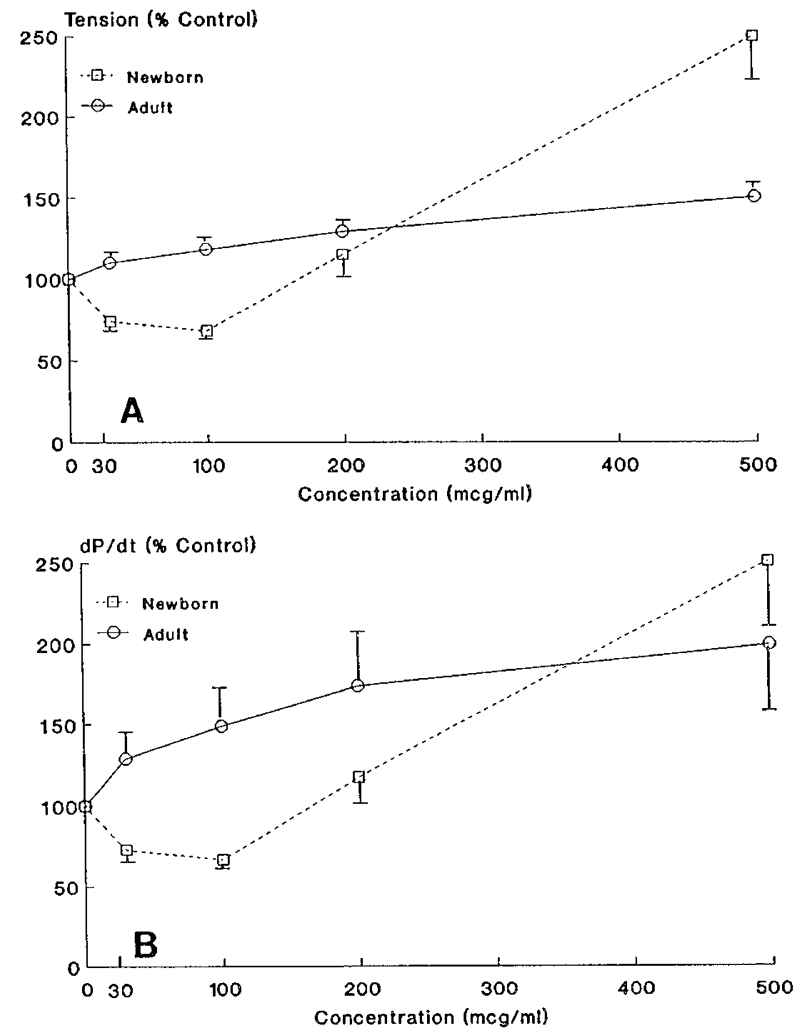

Fig. 2. $A$ shows the relationship between twitch tension (\%-control) and increasing concentrations of amrinone for newborn (squares, $n=7$ ) and adult (circles, $n=6$ ) papillary muscle. Note that tension is a monotonically increasing function of amrinone concentration in the adult. This increase in tension was statistically significant at all amrinone concentrations tested. In the newborn, amrinone caused a decrease in tension at 30 and $100 \mu \mathrm{g} / \mathrm{mL}$. This decrease was statistically significant. Tension at $200 \mu \mathrm{g} / \mathrm{mL}$ was not significantly different from control, and, similar to the adult, tension at $500 \mu \mathrm{g} / \mathrm{mL}$ was significantly greater than control in the newborn. $B$ shows a similar graph for $\mathrm{dP} / \mathrm{dt}$. Once again, note the monotonic increase in $\mathrm{dP} / \mathrm{dt}$ in the adult and a decrease in $\mathrm{dP} / \mathrm{dt}$ at the lowest concentration of amrinone in the newborn. The newborn developed a significant increase in $\mathrm{dP} / \mathrm{dt}$ at the highest amrinone concentration. (Temperature $=23^{\circ} \mathrm{C}$; error bars show the SEM for each value.)

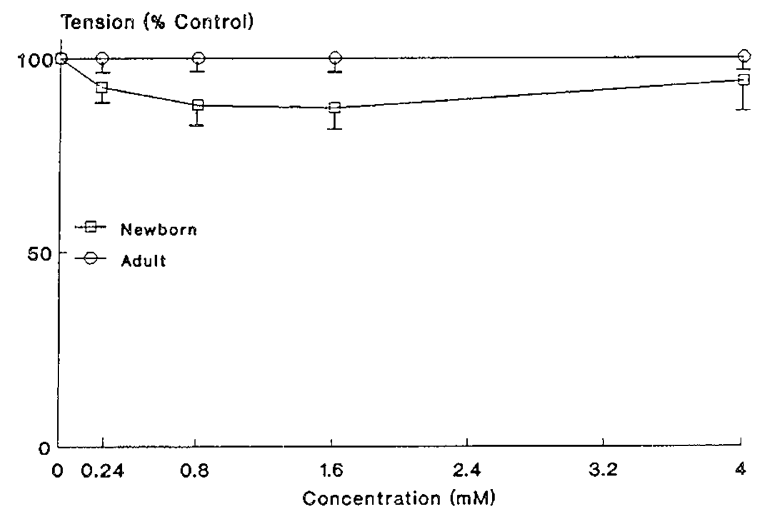

Fig. 3. The effect of lactic acid on twitch tension for both the newborn (squares, $n=5$ ) and the adult (circles, $n=6$ ) is shown. The lactic acid concentrations used are the concentrations used to dissolve a corresponding concentration of amrinone. For example, $0.24 \mathrm{mM}$ lactic acid was used to dissolve $30 \mu \mathrm{g} / \mathrm{mL}$ of amrinone. Note that lactic acid has no effect on tension in the adult. Although there is a tendency toward a decrease in tension with increasing lactic acid concentration in the newborn, this decrease did not reach statistical significance. (Temperature $=23^{\circ} \mathrm{C}$; error bars represent the SEM for each point.)

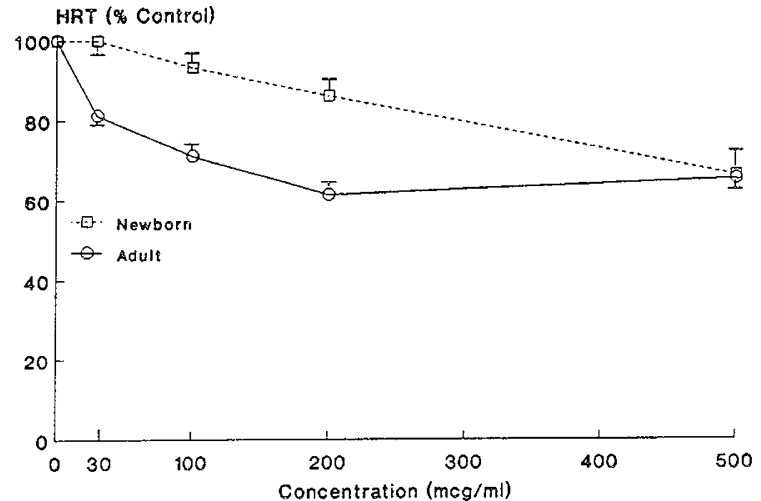

Fig. 4. A graph of HRT as a percentage of control versus amrinone concentration for both newborn (squares, $n=7$ ) and adults (circles, $n=$ 6 ) is shown. Note that in the newborn low concentrations of amrinone, (30 and $100 \mu \mathrm{g} / \mathrm{mL}$ ) had no significant effect on HRT. The decrease in HRT at $200 \mu \mathrm{g} / \mathrm{mL}$ in the newborn approaches statistical significance; however, not until a concentration of $500 \mu \mathrm{g} / \mathrm{mL}$ is HRT significantly decreased in the newborn. In the adult, there in a monotonic decrease in half-relaxation time with increasing amrinone concentration and the decrease is significant at each concentration. (Temperature $=23^{\circ} \mathrm{C}$; error bars represent the SEM; see text for further discussion.)

the voltage clamp group. In these preparations, $30 \mu \mathrm{g} / \mathrm{mL}$ amrinone significantly reduced action potential duration $(390 \pm 11$ to $366 \pm 12 \mathrm{~ms} ; p<0.01$ ).

Voltage clamp experiments. Two-s voltage clamp steps to +10 $\mathrm{mV}$ were imposed on newborn papillary muscles before and after exposure to amrinone concentrations of 30 and $500 \mu \mathrm{g} / \mathrm{mL}$. As summarized in Table $1,30 \mu \mathrm{g} / \mathrm{mL}$ of amrinone had no effect on $\mathrm{T}_{400}, \mathrm{~T}_{\text {tonic }}$, or the $\mathrm{P} / \mathrm{T}$ ratio despite the fact that there was a significant decrease in twitch tension at this concentration. Conversely, $500 \mu \mathrm{g} / \mathrm{mL}$ amrinone significantly increased twitch tension, $\mathrm{T}_{\text {tonic }}$, and $\mathrm{T}_{400}$ but had no effect on the $\mathrm{P} / \mathrm{T}$ ratio (Table 2).

\section{DISCUSSION}

The major finding of these experiments is the demonstration of a biphasic response of the newborn heart to increasing concentrations of amrinone. Consistent with the observations of previous investigators $(9-11)$, peak tension and $\mathrm{dP} / \mathrm{dt}$ were both depressed in the neonate at amrinone concentrations less than $100 \mu \mathrm{g} / \mathrm{mL}$. At $500 \mu \mathrm{g} / \mathrm{mL}$, however, amrinone produced an increase in both peak tension and $\mathrm{dP} / \mathrm{dt}$. This biphasic response raises two interesting questions. First, why does the neonatal heart behave differently from the adult heart at low concentrations of amrinone? Second, why does the neonatal heart respond differently to low and high amrinone concentrations? In an attempt to answer these questions, several possibilities were considered.

Effect of lactic acid. It is unlikely that the negative inotropic effect of amrinone at low concentrations is primarily an effect of lactic acid. Consistent with the findings of Binah et al. (10), the experiments illustrated in Figure 3 suggest that whereas lactic acid tends to have a dose-dependent negative inotropic effect in the newborn, this effect does not reach statistical significance. Thus, whereas the negative inotropic effect of lactic acid may contribute to tension suppression by low dose amrinone in the neonate, other mechanisms must play a role. Moreover, tension suppression by lactic acid is minimal at low concentrations where the negative effect of amrinone is most prominent.

Effects of amrinone on relaxation. It has been suggested that a positive inotropic effect occurs in mature myocardium when the sequestration of $\mathrm{Ca}^{2+}$ by the $\mathrm{SR}$ is enhanced (18-21). This increased $\mathrm{Ca}^{2+}$, when rereleased on subsequent beats, results in increased tension development. Sys et al. (12) conjecture that amrinone acts to enhance the contribution of $\mathrm{Ca}^{2+}$ sequestered by the SR to tension generation in adult myocardium. If this 
Table 1. Effect of low dose amrinone $(30 \mu \mathrm{g} / \mathrm{mL})$ on tension development in newborn myocardium (mean \pm SEM)

\begin{tabular}{lccc}
\hline & Control & Amrinone & $p$ \\
\hline Twitch & $64 \pm 15$ & $56 \pm 14$ & $<0.05$ \\
$\mathrm{~T}_{400}$ & $89 \pm 20$ & $78 \pm 19$ & $>0.10$ \\
$\mathrm{~T}_{\text {tonic }}$ & $110 \pm 24$ & $96 \pm 22$ & $=0.10$ \\
$\mathrm{P} / \mathrm{T}$ ratio & $1.03 \pm .06$ & $1.0 \pm .06$ & $>0.10$ \\
\hline
\end{tabular}

Table 2. Effect of high dose amrinone $(500 \mu \mathrm{g} / \mathrm{mL})$ on tension development in newborn myocardium (mean $\pm S E M$ )

\begin{tabular}{lccc}
\hline & Control & Amrinone & $p$ \\
\hline Twitch & $91 \pm 13$ & $184 \pm 32$ & $<0.05$ \\
$\mathrm{~T}_{400}$ & $128 \pm 25$ & $230 \pm 45$ & $<0.05$ \\
$\mathrm{~T}_{\text {tonic }}$ & $126 \pm 33$ & $250 \pm 52$ & $<0.05$ \\
$\mathrm{P} / \mathrm{T}$ ratio & $1.2 \pm 0.06$ & $1.1 \pm 0.08$ & $>0.10$ \\
\hline
\end{tabular}

were the case, one might expect that neonatal myocardium, whose SR has been shown to be immature functionally $(13,14$, 22 ), would fail to demonstrate a positive inotropic effect in response to amrinone. The finding that low dose amrinone had no effect on HRT in newborn myocardium, while significantly reducing HRT in the adult (an effect that has been reported previously) (23), provides evidence that lower concentrations of amrinone may stimulate the mature but not the immature SR. This lack of stimulation of the SR in the newborn may explain, in part, the absence of a positive inotropic response of immature myocardium to lower doses of amrinone. The negative inotropic effect of low dose amrinone on the neonatal heart, however, cannot be explained in this manner. In addition, the significant decrease in HRT at $500 \mu \mathrm{g} / \mathrm{mL}$ in the neonate suggests a possible role for the SR at this higher concentration.

Effect of action potential configuration on tension development. It has been shown previously that tension development in neonatal heart is more dependent on the degree and duration of depolarization than in the adult (13). Thus, small changes in action potential plateau height and duration may significantly affect tension development in newborn myocardium. At low concentration, amrinone was shown to significantly reduce the duration of the newborn action potential. For this reason, experiments were carried out using the single sucrose gap voltage clamp technique to provide a uniform level and duration of depolarization, and thus eliminate plateau height and duration of the action potential as variables. During voltage clamp steps to the plateau level, tension measurements were made at a time comparable to the normal action potential duration $(400 \mathrm{~ms})$, and at the end of a 2 s clamp step when the tension had reached its final steady state value (see Table 1). Both $\mathrm{T}_{400}$ and $\mathrm{T}_{\text {tonic }}$ were unchanged by the addition of low dose amrinone, despite the fact that twitch tension was significantly reduced in the same group of muscles. This result suggests that the negative inotropic effect of amrinone is the result of changes in the electrical activity of the cell membrane, and not a true alteration of the basic mechanisms of intracellular $\mathrm{Ca}^{2+}$ regulation.

Differential effect of low and high dose amrinone. The positive inotropic effect of high concentrations of amrinone on the neonatal heart might be expected to result from one of two basic mechanisms: 1 ) enhanced activity of the functionally immature sarcoplasmic reticulum; or 2) enhanced $\mathrm{Ca}^{2+}$ influx. The finding that addition of high dose amrinone increased both $\mathrm{T}_{400}$ and $T_{\text {tonic }}$ as well as twitch tension, excludes the possibility that the inotropic effect is due to changes in action potential configuration alone.

It has been shown previously that the $\mathrm{P} / \mathrm{T}$ ratio measured during a long voltage clamp step to the plateau level, is an indicator of the relative contributions of $\mathrm{Ca}^{2+}$ release from the $\mathrm{SR}$ and $\mathrm{Ca}^{2+}$ influx from the extracellular space to tension generation. An increase in the $\mathrm{P} / \mathrm{T}$ ratio indicates enhanced activity of the SR (13). The experiments reported in Table 1 indicate that the $\mathrm{P} / \mathrm{T}$ ratio was unaffected by amrinone. This result suggests that high dose amrinone does not increase tension in the neonatal myocardium by increasing $\mathrm{SR} \mathrm{Ca}^{2+}$ release as compared with $\mathrm{Ca}^{2+}$ influx across the sarcolemma. Rather, it would appear that high concentrations of amrinone increase tension in neonatal myocardium both by increasing $\mathrm{Ca}^{2+}$ influx and by enhancing $\mathrm{Ca}^{2+}$ sequestration and rerelease by the functionally immature SR. This hypothesis is consistent with the previous suggestion that bipyridine derivatives increase tension in adult myocardium via multiple mechanisms (24).

In conclusion, amrinone has been shown to have a differential effect on newborn and adult myocardium. At low doses, amrinone depresses tension in immature myocardium by altering the level and duration of depolarization. At high doses of amrinone, tension development in the newborn is enhanced by a combination of increased transsarcolemmal $\mathrm{Ca}^{2+}$ influx and enhanced uptake and rerelease of $\mathrm{Ca}^{2+}$ from the SR. It is possible that immaturity of receptors, $\mathrm{Ca}^{2+}$ transport systems or the SR may be responsible for the higher concentrations of amrinone needed to achieve a positive inotropic effect in the newborn.

\section{REFERENCES}

1. Alousi AA, Farah AE, Lesher GY, Opalka Jr CJ 1979 Cardiotonic activity of amrinone-win 40680 [5-amino-3, 4-bipyradin-6 (1H)-one]. Circ Res 45:666677

2. LeJemtel TH, Keung E, Sonnenblick EH, Ribner HS, Matsumoto M, Davis R, Schwartz W, Alousi AA, Davolos D 1979 Amrinone: a new non-glycosidic, non-adrenergic cardiotonic agent effective in the treatment of intractable myocardial failure in man. Circulation 59:1098-1 104

. Mancini D LeJemtel T, Sonnenblick E 1985 Intravenous use of amrinone for the treatment of the failing heart. Am J Cardiol 56:8B-15B

4. Honerjager P, Schafer-Korting M, Reiter M 1981 Involvement of cyclic AMP in the direct inotropic action of amrinone. Arch Pharmacol 318:112-120

Endoh M, Yamashita S, Taira N 1982 Positive inotropic effect of amrinone in relation to cyclic nucleotide metabolism in the canine ventricular muscle. J Pharmacol Exp Ther 221:775-783

6. Adams HR, Rhody J, Sutko JL 1982 Amrinone activates $\mathrm{K}^{+}$-depolarized atrial and ventricular myocardium of guinea pigs. Circ Res 51:662-665

7. Sutko JL, Kenyon JL, Reeves JP 1986 Effects of amrinone and milrinone on calcium influx into the myocardium. Circulation 73 (suppl III):III-52-III-58 calcium "Cardiotonic activity of amrinone-win 40680

8. Katz AM 1980 Comments on "Cardiotonic activity of amrin

Binah O, Legato MJ, Danilo Jr P, Rosen MR 1983 Developmental changes in the cardiac effects of amrinone in the dog. Circ Res 52:747-752

10. Binah O Sodowick B, Vulliemoz Y, Danilo Jr P, Rosen M 1986 The inotropic effects of amrinone and milrinone on neonatal and young canine cardiac muscle. Circulation 73 (suppl XII):III-46-YII-5I

11. Ross-Ascuitto N, Ascuitto R, Chen V, Downing SE 1987 Negative inotropic effects of amrinone in the neonatal piglet heart. Circ Res 61:847-852

12. Sys SU, Goenen MJ, Chalant CH, Brutsaert DL 1986 Inotropic effects of amrinone and milrinone on contraction and relaxation of isolated cardiac muscle. Circulation 73 (suppl III):III-25-III-35

13. Klitzner T, Friedman WF 1988 Excitation-contraction coupling in developing Klitzner T, Friedman WF 1988 Excitation-contraction coupling in developing
mammalian myocardium: evidence from voltage clamp studies. Pediatr Res 23:428-432

14. Klitzner TS, Friedman WF 1989 A diminished role for the sarcoplasmic reticulum in newborn myocardial contraction: effects of ryanodine. Pediatr Res 26:98-101

15. Morad M, Sanders C, Weiss J 1981 The inotropic actions of adrenaline on frog ventricular muscle: relaxing versus potentiating effects. $J$ Physiol 311:585-604

16. Morad M Orkland RK 1971 Excitation-contraction coupling in frog ventricle: evidence from voltage clamp studies. J Physiol 219:167-189

17. Morrison DF 1972 The analysis of a single sample of repeated measurements Biometrics 28:55-71

18. Morad M, Goldman Y 1973 Excitation-contraction coupling in heart muscle: membrane control of development of tension. Prog Biophys Mol Biol 27:257-313

19. Chapman RA 1979 Excitation-contraction coupling in cardiac muscle. Prog Biophys Mol Biol 35:1-52

20. Sutko JL, Bers DM, Reeves JP 1986 Postrest intropy in rabbit ventricle: $\mathrm{Na}^{+}$ $\mathrm{Ca}^{2+}$ exchange determines sarcoplasmic reticulum $\mathrm{Ca}^{2+}$ content. Am J Physiol 250:H654-H661

21. Langer GA 1986 Calcium at the sarcolemma: its role in control of myocardial contraction. In: Nathan RD (ed) Cardiac Muscle: The Regulation of Excitation and Contraction. Academic Press, Orlando, FL, pp 269-281

22. Mahoney L 1988 Maturation of calcium transport in cardiac sarcoplasmic reticulum. Pediatr Res 24:639-643

23. Morgan JP, Lee NKM, Blinks JR 1980 Mechanisms of inotropic action of amrinone: unusual pattern of $\mathrm{Ca}^{2+}$ transients as detected with aequorin. Fed Proc 39:854

24. Alousi AA, Johnson DC 1986 Pharmacology of the bipyridines: amrinone and milrinone. Circulation 73 (suppl III):III-10-III-24 